\title{
ADDED AND FREE SUGARS: REVIEW IN THE LITERATURE OF ESTIMATED INTAKES AND ITS MAIN FOOD SOURCES
}

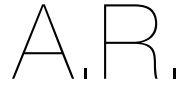
ARTIGO DE REVISÃO

\section{EPIUnit - Instituto} de Saúde Pública da Universidade do Porto, Rua das Taipas, n. ${ }^{\circ} 135$ 4050-600 Porto, Portugal

2 Departamento de Ciências da Saúde Pública e Forenses e Educação Médica da Faculdade de Medicina da Universidade do Porto

Alameda Prof. Hernâni

Monteiro,

4200-319 Porto, Portugal

${ }^{3}$ Faculdade de Ciências da Nutrição e Alimentação da Universidade do Porto, Rua Dr. Roberto Frias, 4200-465 Porto, Portugal

‘Endereço para correspondência:

Ana Rita Marinho

EPIUnit - Instituto de Saúde Pública da Universidade do Porto,

Rua das Taipas, n. ${ }^{\circ} 135$, 4050-600 Porto, Portuga anarita.marinho@ispup.up.pt

Histórico do artigo:

Recebido a 4 de setembro de 201 2019

\author{
AÇÚCARES ADICIONADOS E LIVRES: UMA REVISÃO \\ DA LITERATURA DO CONSUMO E PRINCIPAIS FONTES \\ ALIMENTAR
}

Ana Rita Marinho ${ }^{1,2 *}$. Elisabete Ramos 1,2. Duarte Torres ${ }^{1,3 ;}$ Carla Lopes ${ }^{1,2}$

\section{ABSTRACT}

Excessive sugar intake in the population has become an increasingly Public Health issue, in particular, added and free sugars. However, there is still insufficient information on added and free sugars intake across populations and the main food sources at different age groups, namely due to inconsistency on the definitions and lack of a systematic approach to estimate its content in foods. The present review aims to explore the available data in the literature on added and free sugars intake at the population level and its main food sources, discussing definitions and assessment methods. Emerging evidence suggests an association between free sugar intake and several health-outcomes, which motivated several health authorities to recommend a limit of added and free sugars intake below $10 \%$ of energy intake. National dietary surveys (including data from Portugal) reported that children and adolescents had the highest intake of added and free sugars, thus showing the lowest adherence to recommended values (free sugar intake below $10 \%$ of total energy intake). The main food sources contributing to added and free sugars intake were mostly processed foods, such as sweets, cakes and soft drinks. Accordingly, standardized definitions and methods for reproducible research on the estimation of added sugars intake are needed, in order to allow comparisons across different populations. Also, the information from regular dietary surveys is required to support the development and assessment of policies' effectiveness.

\section{KEYWORDS}

Added sugars, Dietary surveys, Free sugars, Sugars

RESUMO

O consumo excessivo de açúcares adicionados na população tornou-se um problema emergente de Saúde Pública. No entanto, dados de consumo alimentar de açúcares adicionados e livres na população e as suas principais fontes ainda são insuficientes, particularmente devido a inconsistências na sua definição e à ausência de uma metodologia sistemática para estimar o seu conteúdo nos alimentos. A presente revisão pretende examinar estudos a nível populacional que reportem o consumo de açúcares adicionados e livres, assim como as principais fontes alimentares, analisando definições e métodos para a sua estimativa. Estudos recentes sugerem uma associação entre o consumo de açúcares livres e diversos problemas de saúde, o que motivou diversas organizações de saúde a recomendar uma ingestão diária de açúcares adicionados e livres inferior a 10\% do valor energético total. Dados de consumo alimentar provenientes de inquéritos nacionais alimentares, incluindo Portugal, reportaram que as crianças e os adolescentes apresentaram um elevado consumo de açúcares adicionados e livres, e, por conseguinte, uma menor adesão às recomendações (consumo de açúcares livres < 10\% do valor energético). As principais fontes alimentares que contribuíram para o consumo de açúcares livres e adicionados foram principalmente alimentos processados, como doces, bolos e refrigerantes. Assim, reforçamos a necessidade de definições consistentes entre estudos e metodologias de cálculo do teor de açúcares adicionados reprodutíveis, de forma a que a comparação entre populações possa ser estabelecida. Adicionalmente, a realização regular de inquéritos alimentares nacionais é imprescindível para suportar o desenvolvimento e a avaliação da eficácia de políticas alimentares.

PALAVRAS-CHAVE

Açúcares adicionados, Inquéritos alimentares, Açúcares livres, Açúcares

\section{INTRODUCTION}

Despite carbohydrate importance in energy metabolism, the effect of some subtypes of sugar has raised concerns about their role on energetic contribution, post-prandial metabolic response and satiety regulation (1, 2). Excessive sugar intake in the population has become a Public Health issue. Regarding added and free sugars intake, dietary recommendations have been updated and limits have been shortened, mostly in the last years, due to emerging evidence that supports the association between added and free sugars intake and several health outcomes, mainly weight gain, type II diabetes, cardiovascular diseases, metabolic disorders and dental decay $(3,4)$. Several health authorities have defined the different types of dietary sugar considering the nature of food matrix and their physiological/ functional properties $(5,6)$. However, assessing added 
and free sugars content in foods and population's intake constitutes a challenge, due to a lack of use of a standardized methodology to estimate its content, the inconsistency of terms used in the definition of the type of "sugar" and the fact that definitions are frequently omitted across studies. To our knowledge, even though total and added sugar intakes have already been published, a review on estimates of total, added and free sugars across the world has never been issued (7).

Therefore, it is of the utmost relevance to develop Public Health strategies, which include changes of external/environmental factors and promotes healthier food choices, such as Portugal has been implementing. The Portuguese National Programme for the Promotion of Healthy Eating (PNPAS) is the first national organized strategy for the promotion of healthy eating. Among other objectives, it aimed to modulate the supply of certain foods, particularly high in sugar, fat and salt, and their availability in public settings (such as schools and health care services) (8). Based on this strategy, in 2016 measures were adopted to limit the availability of food with excessive salt and sugar in vending machines (9), further extended to bars and restaurants in health care services. In 2017, the taxation of sugar-sweetened beverages and regulation towards availability of foods with high contents of sugar was instituted and portrayed in the Portuguese legislation $(9,10)$. Preliminary analysis, based on data from industry, aimed to evaluate the impact of the previously mentioned policies, reported a decrease of $4.3 \%$ in sales of soft drinks (11).

Dietary surveys constitute a crucial evidence-based tool to assess the population's intake before and after the implementation of such food policies. Thus, this review aims to explore the available data in the literature on added and free sugars intake at the population level and its main food sources, discussing definitions and assessment methods.

\section{Sugar's Definition}

Dietary carbohydrates chemical classification was proposed in 1997 at the Joint FAO/WHO Expert Consultation on Carbohydrates in Human Nutrition (12). The chemical classification encompasses molecular size, number of monomeric units, type of linkage ( $a$ or non- $a$ ) and character of individual monomers (13), dividing carbohydrate in three groups: (i) sugars ( 1 to 2 monomers plus polyols); (ii) oligosaccharides (short-chain carbohydrates, ranging from 3 to 9 monomers); (iii) polysaccharides (more than 10 monomers). Chemical classification is useful for labelling and for accurate measurement of carbohydrate content, yet does not facilitate the nutritional characterization of dietary carbohydrates based on their physiological influence on health.

Conventionally, the term "sugars" is used to describe mono- and disaccharides present in food. However, other terms were developed for labelling purposes (total sugars), to distinguish their origin (extrinsic and intrinsic sugars in United Kingdom or free sugars) and their utility in the food industry as a sweetener or as a palatability improvement element (added sugars). Then, other dimensions should be acknowledged when classifying carbohydrates, such as the nature of the food matrix (biological origin, food processing) and physiological properties, such as resistance to digestion, absorption in the intestine, glycaemic response, satiety response, among others. Classification based on physiological properties enhances the focus on health benefits of carbohydrates and helps to identify foods which may take part in a healthy diet (13). However, several physiological properties could be attributed to more than one subgroup of carbohydrates, according to the chemical classification. Consequently, a wide range of terminologies has been used within carbohydrates: complex carbohydrates, sugars, prebiotics, resistant starch, modified starch, dietary fibre, soluble and insoluble, available and unavailable carbohydrates, glycaemic carbohydrate and non-glycaemic carbohydrate $(13,14)$.
The demand to distinguish between sources of sugar has been recognized by several health authorities and dietary recommendations have been published using the following terms to define the type of "sugars":

(i) Total Sugar: all monosaccharides and disaccharides, excepting polyols (15);

(ii) Added Sugar: defined in 2009 by EFSA as "sucrose, fructose, glucose, starch hydrolysates (glucose syrup, high-fructose corn syrup) and other isolated sugar preparations used as such or added during food preparation and manufacturing" (16);

(iii) Free Sugars: first referred to any sugar, which was free or does not bound, it was later redefined as "all monosaccharides and disaccharides added to foods by the manufacturer, cook and consumer, plus sugar naturally present in honey, syrups and fruit juices" by WHO (3);

(iv) Intrinsic Sugars: sugars naturally enclosed in the cellular structure of foods (17);

(v) Extrinsic Sugar: sugars not incorporated or contained into a cellular structure of foods (17);

(vi) Non-milk extrinsic sugars (NMES): sugars added to foods and sugars naturally present in fruit juices (17), especially used in the United Kingdom $(\mathrm{UK})$.

Among studies, the term "sugar" may also be used to refer to table sugar or sucrose. Due to this inconsistency across terms in literature and the lack of clear definitions in published studies, estimating added and free sugars is a challenge for researchers (18). As mentioned by Azaïs-Braesco et al., reporting sucrose as the source of sugar intake instead of total, added and free sugar, could create misunderstandings, since sucrose can also be naturally present in foods such as fruit (7).

\section{Methods of Assessment of Added and Free Sugars}

Even though, recent analytical methods have been developed in order to improve the reliability of estimating added sugar content of foods, the high cost and the incapacity to distinguish between added sugar and naturally present sugar have been described as barriers to estimate them accurately (19). This enables to determine added sugar intake across populations and to assess its association with several health outcomes. Still, several methodologies have been used to estimate added sugar content of foods $(20,21)$. However, the underlying principle of these methods lacked precision (added sugars=total sugars-naturally occurring sugars), were inconsistent or required subjective decisions. For this reason, Louie et al. (19) described a 10-step methodology for added sugars content of foods. This methodology attributed an estimated value of added sugar to each food item, according to their natural sugar or added sugar content. Most of the steps were based on objective decisions, however, when no information was available, the estimation of added sugar content was based on subjective steps considering recipes, similar products or other (example step 7 to 10). This methodology proposed the following steps: (step 1) to foods with $0 \mathrm{~g}$ of total sugars, $0 \mathrm{~g}$ of added sugars was assigned; (step 2) to foods unprocessed or minimally processed with no added sugar, Og of added sugars was assigned; (step 3) to foods that contained minimal amounts of naturally occurring sugars, $100 \%$ of total sugars was assigned as added sugar; (step 4) calculated formula based on a standard recipe used in the food composition database, where added sugar contents of all ingredients were available from the previous steps; (step 5) calculated formula based on comparison with values from the unsweetened variety; (step 6) decision based on the availability of analytical data, when food contains malted cereals, lactose and maltose data, added sugar content=total sugars-lactose-maltose; (step 7) values from similar product(s) within local or international food composition databases. Added sugar content=total sugars ${ }^{\star}$ proportion of sugars as added; (step 
8) subjective estimation based on ingredients and/or common recipes; (step 9) calculation based on the standard recipe that includes ingredients with values assigned at step 5 to 8 , using the calculated formula; (step 10) assigned $50 \%$ of total sugars as added sugars if estimation of added sugars was impossible from the previous steps.

To estimate free sugar, according to the WHO definition (3), added sugars were summed with sugars naturally presented in honey, syrups, fruit juices and fruit juice concentrates. This methodology aimed to standardize an objective approach to improve epidemiological studies. EFSA Panel on Nutrition, Dietetic Products and Allergies (NDA Panel) (22) has supported the use of this methodology in national dietary surveys.

\section{Guidelines to Limit Added and Free Sugars Intake}

Recommendations aim to compare population's intake with a reference value and to provide information to be used by policy-makers, in order to promote Public Health interventions, which ultimately focuses on reducing the risk of disease across populations. Although recommendations have set a consistent benchmark of both added and free sugars intake below $10 \%$ of total energy intake over the last years $(3,23), \mathrm{WHO}$ published recently an updated recommendation to further reduction of free sugar intake below $5 \%$ of total energy intake (TEI) (3). The reason for this "conditional recommendation" relied on consistent findings regarding free sugar contribution to the overall density of diets and positive energy balance, particularly sugar-sweetened beverages (SSB), leading to weight gain (4), dental caries and increased risk of NCDs (3).

Estimated Intakes of Added and Free Sugars Across Literature Several estimates of added and free sugars intake across populations reported in the literature were based on data from National Dietary Surveys, which are fundamental to collect detailed quantitative information on food consumption, to monitor the nutritional status of a population and to provide information on adherence to food policies, allowing ongoing surveillance (22).

A published review of sugar's consumption examined total and added sugars intake across the world, however, the number of countries with estimates from national dietary surveys was scarce (24). From 10 European countries, Australia and New Zealand and United States of America (USA), only four countries reported specifically added sugar intake: Denmark, Norway, USA and UK (in the form of non-milk extrinsic sugars - NMES). Comparing with previous surveys conducted in those countries, a decrease in the percentage of energy achieved from added sugar intake was reported at all age groups, except in Danish adults, whom consumption was stable (24). Data from the National Health and Nutrition Examination Survey (NHANES), in the USA, showed that the percentage of daily energy from added sugars has also declined among adults from $18 \%$ in $1999-2000$, to $15 \%$ in $2007-2008$ to $13 \%$ in 2007 2010 (25), even though intakes were still above the recommended values for the American population.

Within the European framework, Azaïs-Braesco et al. (7) underlined the large difference of added sugar/NMES contribution to TEl between children and adults. In adults, added sugar (or NMES in UK) contribution ranged between $7.3 \%$ TEl in Norway to 11.4\% TEl in UK, while in children ranged from $11.0 \%$ TEl in Denmark to the highest contribution around 17\% TEl in The Netherlands. In a nationally representative sample of the Dutch (28) and Spanish (30) population, differences in free sugar intake (\%TEl) were observed with age. Dutch boys and girls with 7 to 13 years showed the highest contribution (approximately 20\% TEI) and Spanish adolescents showed a higher contribution of free sugars (boys: $9.6 \%$ TEl and girls: $10.8 \%$ TEI) than adults (7.1\% TEI) and elderly (5.1\% TEI). Additionally, in Australia (31), adolescents with 14-18 years showed the highest contribution of free sugars (around 15\% to TEl).

Since WHO reinforced the importance of reducing free sugar intake and updated a previous guideline, advising to a more restrictive cut-off of daily energy intake from free sugars ( $<5 \% \mathrm{TEI}$ ) (3), two studies have been recently published $(26,27)$. In comparison to the $\mathrm{WHO}$ recommendation of a free sugar intake contribution $<10 \% \mathrm{TEl}, 41 \%$ of French adults showed excessive free sugars intake (26). Also, individuals with excessive free sugar consumption were 10 years younger than individuals who showed acceptable free sugar intake, showing age-related trends in sugar consumption. Moreover, in New Zealand (28), 73\% of younger adults aged $15-30$ years and $49 \%$ of individuals with older ages (aged over 71 years) did meet the recommendation.

\section{Estimated Intakes of Added and Free Sugar Across in Portugal} In the National Food, Nutrition and Physical Activity Survey (IAN-AF 2015-2016) of the Portuguese General Population, the mean intake of total sugar was $84 \mathrm{~g} /$ day, contributing to $18.5 \%$ of the total energy intake (TEI) and the highest contribution was found among children (24.9\% TEI) and adolescents (20.2\% TEI). In relation to free sugars intake, mean intake in the population was $35 \mathrm{~g} /$ day contributing to $7.5 \%$ TEl. Similarly, children and adolescents showed the highest contribution to TEI ( $9.6 \%$ and $10.5 \%$, respectively).

In Portugal, almost $25 \%$ of the total population (including children) showed an intake of free sugar above $10 \%$ TEl. Children (40.7\%) and adolescents (48.7\%) had the highest prevalence of inadequate intake of free sugar (29).

Main Food Sources of Added and Free Sugar Across Literature A recent review of added and free sugars intake in the European population (7) evaluated food groups which most contributed to the daily intake of added sugar in adults and children. Both in children and adults, the main food sources of added sugar were provided by the food group sweet products (chocolates, cakes/cookies, sugar/honey/jam/syrups, confectionery, icecream) accounting with $45 \%-50 \%$ to TEl in children and $47 \%-61 \%$ to TEl in adults. Within adults from The Netherlands, France and UK, sugar/ honey/jam/syrups had higher contributions, followed by cakes/cookies. Dairy products, mainly yoghurts, also showed a considerable contribution (16 to $18 \%$ ), particularly in French children. Beverages (fruit/vegetable juices and soft drinks) were the second main food source of added sugar, excepting for French adult women. In children, soft drinks were the major contributor, especially in the Netherlands (girls 26\% to TEl and boys 30\% to TEI). More recently, Spain and The Netherlands published two studies considering sources of added sugar and free sugar in their population, by age category and sex. The main food sources of free sugars were similar to the main food sources of added sugars. Spanish adolescents (13-17 years) and adults (18-64 years) also showed considerable contributions from soft drinks: 30\% TEl and 26\% TEl, respectively. In contrast, the elderly had higher contributions from table sugar (25\% to TEl) (30). In the Dutch population, soft drinks lead the top sources of free sugar across all ages, in addition to fruit/vegetable juices (27).

Apart from Europe, in Australia, SSB provided the highest contribution of added sugar, followed by cakes/biscuits/pastries and sugar/sweet spreads, both in children (2-18 years) and adults (over 19 years) (31). Similarly, in USA, the primary source of added sugar in the population was beverages. Nevertheless, differences were found regarding the type of beverages across age groups. Among children from 2 to 8 years, fruit juice based and fruit beverages were the main contributors, while in adolescents (9-18 years) and adults (over 19 years) were soft drinks (such as sodas, colas) (32).

\section{Main Food Sources of Added and Free Sugar in Portugal}

Among the Portuguese population, the main food source of free sugar 
was table sugar (21.4\%), followed by sweets (16.7\%), soft drinks (11.9\%), cakes (10.4\%) and yoghurts/other fermented milk (10.2\%). In children under 5 years, the main source of added and free sugars were yoghurts, infant cereals and formulas, sweets and cookies. In children over 5 years and adolescents, the main source of added and free sugar were sweets, soft drinks yoghurts and breakfast cereals. Table sugar was the major source among adults/elderly (29, 33).

\section{CRITICAL ANALYSIS}

The majority of studies reported total sugar instead of added or free sugars. Moreover, a small number of them described the main food sources by different age-groups and using national representative samples. In most of the countries, the main food sources contributing to both added and free sugars intake were processed foods and the age-groups with the highest intake were children and adolescents. This highlights the need for the development of Public Health strategies, targeting the main contributors of added and free sugar intake considering age, and actions that lead individuals to modify their food intake/choices. Therefore, it becomes essential to ascertain the groups of the population at risk, the prevalence of inadequate intake and the main food sources by age.

Moreover, the lack of use of a standardized methodology to estimate added sugar content in food prevents proper comparison across countries and adequate assessment of dietary intake in the population. For this reason, it is crucial to adopt a systematic methodology to estimate added sugar content in foods at the population level.

\section{CONCLUSIONS}

The lack of a systematic methodology to estimate added and free sugar intake at population level inhibits proper comparisons across studies. Thus, we reinforce the need to harmonize methodologies of added and free sugars assessment in epidemiological studies. Data from national dietary surveys in some countries, including Portugal, reported that children and adolescents had the highest intake of added and free sugar, mainly from processed foods, thus showing the lowest adherence to recommended values. Even though Portugal has been implementing strategies to promote healthier dietary habits, more information from dietary surveys repeated over time is needed, in order to evaluate the effectiveness of the implemented policies.

\section{REFERENCES}

1. Jebb SA. Carbohydrates and obesity: from evidence to policy in the UK. Proceedings of the Nutrition Society. 2015;74(3):215-20.

2. Ludwig DS. The glycemic index: Physiological mechanisms relating to obesity, diabetes, and cardiovascular disease. JAMA. 2002;287(18):2414-23.

3. World Health Organization. Guideline: Sugars intake for adults and children. Geneva. 2015. 4. Te Morenga L, Mallard S, Mann J. Dietary sugars and body weight: systematic review and meta-analyses of randomised controlled trials and cohort studies. BMJ : British Medical Journal. 2013;346.

5. Mann J, Cummings JH, Englyst HN, Key T, Liu S, Riccardi G, et al. FAO/WHO Scientific Update on carbohydrates in human nutrition: conclusions. European Journal Of Clinical Nutrition. 2007;61:S132.

6. Scientific Advisory Committee on Nutrition. Carbohydrates and Health. London. 2015. 7. Azaïs-Braesco V, Sluik D, Maillot M, Kok F, Moreno LA. A review of total and added sugar intakes and dietary sources in Europe. Nutrition Journal. 2017;16(1):6.

8. Graça P, Gregório MJ, Mendes de Sousa S, Carriço J, Correia A, Salvador C. The Portuguese National Programme for the Promotion of Healthy Eating: 2012-2015. Public Health Panorama; 2016. p. 117-247.

9. Portuguese Legislation. Integrated Strategy for the Promotion of Healthy Eating. Order $n^{\circ}$. 11418/2017 of the 29th of December 2017 (Portuguese Official State Gazette n. ${ }^{\circ}$ 249). 2017. 10. Lawn. ${ }^{\circ}$ 42/2016, 28 of December of 2016, (Portuguese Official State Gazetten. ${ }^{\circ}$ 248). 2016. 11. Graça P, Gregório MJ, Mendes de Sousa S, Camolas J. Alimentação Saudável,
Desafios e Estratégias 2018. Lisbon: Directorate General Health; 2018.

12. World Health Organization, Food and Agriculture Organization of the United Nations. Carbohydrates in human nutrition. Report of a Joint FAOMHO Expert Consultation. FAO Food Nutr Pap. Rome, Italy:: Report of a Joint FAOMHO Expert Consultation; 1998. p. 1-140. 13. Cummings JH, Stephen AM. Carbohydrate terminology and classification. European Journal Of Clinical Nutrition. 2007;61:S5.

14. Englyst KN, Liu S, Englyst HN. Nutritional characterization and measurement of dietary carbohydrates. European Journal Of Clinical Nutrition. 2007;61:S19.

15. European Food Safety Authority. Protocol for scientific opinion on sugars. EFSA Journal (draft).

16. European Food Safety Authority. Review of labelling reference intake values Scientific Opinion of the Panel on Dietetic Products, Nutrition and Allergies on a request from the Commission related to the review of labelling reference intake values for selected nutritional elements. EFSA Journal. 2009;7(5):1008:1-14.

17. Department of Health. Dietary Sugars and Human Disease. London: Her Majesty's Stationery Office; 1989.

18. Newens KJ, Walton J. A review of sugar consumption from nationally representative dietary surveys across the world. Journal of Human Nutrition and Dietetics. 2016;29(2):225-40

19. Louie JCY, Moshtaghian H, Boylan S, Flood VM, Rangan AM, Barclay AW, et al. A systematic methodology to estimate added sugar content of foods. Eur J Clin Nutr. 2015;69(2):154-61.

20. Kelly S. A. M., Moynihan P. J., Rugg-Gunn A. J., Summerbell C. D. Review of methods used to estimate non-milk extrinsic sugars. Journal of Human Nutrition and Dietetics. 2003;16(1):27-38.

21. Roodenburg AJC, Popkin BM, Seidell JC. Development of international criteria for a front of package food labelling system: the International Choices Programme. European Journal of Clinical Nutrition. 2011;65(11):1190-200.

22. European Food Safety Authority. Guidance on the EU Menu methodology. EFSA Journal. 2014;12(12):3944.

23. USDA. Dietary Guidelines for Americans 2015-2020. Eight edition. 2015. Available from: http://health.gov/dietaryguidelines/2015/guidelines/. Accessed 04 July 2016.

24. Wittekind A, Walton J. Worldwide trends in dietary sugars intake. Nutr Res Rev. 2014;27(2):330-45.

25. Welsh JA, Sharma AJ, Grellinger L, Vos MB. Consumption of added sugars is decreasing in the United States1-4. The American Journal of Clinical Nutrition. 2011;94(3):726-34.

26. Lluch A, Maillot M, Gazan R, Vieux F, Delaere F, Vaudaine S, et al. Individual Diet Modeling Shows How to Balance the Diet of French Adults with or without Excessive Free Sugar Intakes. Nutrients. 2017;9(2):162.

27. Sluik D, van Lee L, Engelen Al, Feskens EJ. Total, Free, and Added Sugar Consumption and Adherence to Guidelines: The Dutch National Food Consumption Survey 2007-2010. Nutrients. 2016;8(2):70.

28. Kibblewhite R, Nettleton A, McLean R, Haszard J, Fleming E, Kruimer D, et al. Estimating Free and Added Sugar Intakes in New Zealand. Nutrients. 2017;9(12):1292. 29. Lopes C, Torres D, Oliveira A, Severo M, Alarcão V, Guiomar S, et al. Inquérito Alimentar Nacional e de Atividade Física, IAN-AF 2015-2016: Relatório de resultados. Universidade do Porto; 2017.

30. Ruiz E, Rodriguez P, Valero T, Ávila JM, Aranceta-Bartrina J, Gil Á, et al. Dietary Intake of Individual (Free and Intrinsic) Sugars and Food Sources in the Spanish Population: Findings from the ANIBES Study. Nutrients. 2017;9(3):275.

31. Lei L, Rangan A, Flood VM, Louie JCY. Dietary intake and food sources of added sugar in the Australian population. British Journal of Nutrition. 2016;115(5):868-77.

32. Bailey R, Fulgoni V, Cowan A, Gaine P. Sources of Added Sugars in Young Children, Adolescents, and Adults with Low and High Intakes of Added Sugars. Nutrients. 2018;10(1):102.

33. Marinho AR, Severo M, Correia D, Lobato L, Vilela S, Oliveira A, et al. Total, added and free sugar intakes, dietary sources and determinants of consumption in Portugal: the National Food, Nutrition and Physical Activity Survey (IAN-AF 2015-2016). Public Health Nutrition. 2019 Sep; 5:1-13. 